\title{
Subjective Perception of Sports Performance, Training, Sleep and Dietary Patterns of Malaysian Junior Muslim Athletes during Ramadan Intermittent Fasting
}

\author{
Rabindarjeet Singh*" , PhD; Ooi Cheong Hwa ${ }^{2}$, MSc; Jolly Roy ${ }^{2}$ PhD; Chai Wen Jin $^{2}$, BSc; Siti Musyrifah Ismail ${ }^{2}$, MSc; \\ Mohamad Faizal Lan², BSc; Loo Lean Hiong², BSc; Abdul-Rashid Aziz ${ }^{3}$, BPE
}

Authors' Affiliation:

1. Advanced Medical and Dental Institute, Universiti Sains Malaysia, Bertam, 13200 Kepala Batas, Penang, Malaysia

2. National Sports Institute of Malaysia, Bukit Jalil, 57000 Kuala Lumpur, Malaysia

3. Singapore Sports Institute, Singapore Sports Council, Singapore 397799, Singapore

\footnotetext{
* Corresponding Author; Address: Healthy Lifestyle Cluster, Advanced Medical and Dental Institute, Universiti Sains Malaysia, Bertam, 13200 Kepala Batas, Penang, Malaysia

E-mail: rabindar@amdi.usm.edu.my
}

Received: May 09, 2011

Accepted: Aug 05, 2011

Key Words: Subjective Perception; Ramadan Fasting; Sleep Patterns; Dietary Intake; Training

\begin{abstract}
Purpose: To examine the subjective perception of daily acute fasting on sports performance, training, sleep and dietary patterns of Muslim athletes during the Ramadan month.

Methods: Seven hundred and thirty-four (411 male and 323 female) Malaysian Junior-level Muslim athletes (mean age $16.3 \pm 2.6$ y) participated in the survey which was designed to establish the personal perception of their sport performance, sleep pattern, food and fluid intake during Ramadan fasting. The survey was conducted during and immediately after the month of Ramadan in 2009.
\end{abstract}

Results: Twenty-four percent of the athletes perceived that there was an adverse effect of the Ramadan fast on their sporting performance and $\mathbf{2 9 . 3 \%}$ reported that quality of training during Ramadan was also negatively influenced. Majority $(48.2 \%)$ of the athletes stated that Ramadan fasting did not affect their normal sleep pattern but $66.6 \%$ of them complained of sleepiness during the daytime. Half of the athletes (41.4\%) maintained the caloric intake during Ramadan as they normally would with the majority of them $(76.2 \%)$ reporting that they consumed more fluids during Ramadan.

Conclusions: Overall, Malaysian Junior-level Muslim athletes showed diverse views in their perception of changes in their training, sleep and dietary patterns during Ramadan fast. These individual differences probably indicate differences in the athletes' adaptability and coping strategies during fasting and training in Ramadan.

Asian Journal of Sports Medicine, Volume 2 (Number 3), September 2011, Pages: 167-176

\section{INTRODUCTION}

$\mathrm{E}$ ach year during the Islamic month of Ramadan, able-bodied Muslims engage in observing fast from dawn to sunset daily. Eating and drinking are permissible during the nocturnal hours, with no restrictions on the amount or type of food or fluid that can be consumed. In the tropics, this implies a daily fasting of between $\sim 12-14 \mathrm{~h}^{[1]}$. Typically, Muslims consume the majority of their daily nutrient intake at two sittings, the first meal just before sunrise (i.e. the sahur meal), and the second meal at the breaking of the day's fast (i.e. the iftar meal). The issue of Ramadan fasting and sports participation is not new and most Muslim athletes tend not to refrain from training and competing during Ramadan (e.g. Olympic Games 
London 2012). However, the adherence to socioreligious practices during this period can potentially lead to disruptions in the normal routine, which could have physiological and/or psychological consequences for athletes ${ }^{[2]}$.

Eighty-eight percent of Malaysian national athletes are Muslims. These athletes continue to train during the Ramadan month and the impact of Ramadan fasting on training and exercise performances have been shown to be mixed. Some studies have indicated that strength, anaerobic and high-intensity aerobic performances are adversely affected ${ }^{[2,3]}$. The lack of food and fluids as well as accumulated sleep deficit during daytime were cited as possible factors that could compromise exercise performance during Ramadan ${ }^{[2,3]}$. In addition, Muslim athletes have also reported an increase in their subjective feelings of fatigue, malaise, lethargy and mood swings which, could lead to their inability to sustain physical efforts, especially during highintensity exercise ${ }^{[4-7]}$. In contrast, other studies have shown no impact of Ramadan fasting on Muslim athletes' exercise performances ${ }^{[1,2]}$. A suggested reason for this observation is that these Muslim athletes are able to cope, both psychologically and physically, with the perturbations of Ramadan fasting by adapting and/or modifying their routine lifestyle and behaviour patterns ${ }^{[8,9]}$. Such strategies include consuming more food and fluid during the permissible period of the day, reducing other non-essential physical activities, focusing on training quality and not quantity, sleeping early or taking daytime naps, and maintaining an overall positive mental perspective of the Ramadan fast $^{[10]}$. It was further argued that Muslim athletes have experienced fasting and training simultaneously for many years and would have through "trial and error" identified specific needs and strategies that they are comfortable with ${ }^{[10]}$. It must be highlighted that in that study, the subjects were Senior-level national athletes and the number of subjects were less than 170. Junior, as compared to Senior-level athletes, may possess limited knowledge and experience to cope with the perturbations of Ramadan fasting, due to their relatively limited years of competitive and training exposure. To date, there has been no large scale survey conducted with the purpose of identifying factors that would affect Junior-level national athletes in their training or competition during the Ramadan fasting. Thus the aim of this study was to gain further understanding on the subjective perception of the impact of Ramadan fasting on sports performance and training as well as the associated changes in the behavioural and training practices. We envisage that the information obtained from this survey will provide the coaches and athletes with useful information.

\section{METHODS AND SUBJECTS}

\section{Participants:}

Seven hundred and thirty-four Malaysian Junior-level Muslim athletes (mean age $16.3 \pm 2.6 \mathrm{y}$ ), from different sports participated in the survey questionnaire. They comprised the backup cohort of athletes for the Senior-level national squads. At the time of the study, all of the athletes were involved either in the state, national sports associations or national sanctioned training programmes of the National Sports Council of Malaysia. The demographic characteristics of the participants are presented in Table 1. The study was approved by the Institutional Research Committee of the National Sports Institute of Malaysia and the Research Ethics Committee (Human) of Universiti Sains Malaysia.

\section{Data collection and analysis:}

The survey questionnaire was administrated at the various state satellite training centres of the National Sports Institute. The survey was conducted during the last two weeks and within two weeks after the end of the Ramadan fasting month of 2009. The participants were informed of the objectives of the study and were requested to respond to the questions with honesty; participants were assured of the confidentiality of all their responses. Each participant responded to all the questions in Bahasa Malaysia (which is the national language of the country). The survey consisted of questions to establish the following aspects of the individual: personal particulars, sports participation and training background, subjective perception on the effects of Ramadan fasting on sport performance and 
training, sleep behaviour and pattern and the amount of food and fluid intake during Ramadan fasting. An investigator was available throughout the data collection session to provide clarification or to answer any queries on the survey.

The present survey questionnaire has been used in a previous Ramadan study ${ }^{[11]}$. Item analysis of questions relating to training patterns indicated Cronbach's alpha range between 0.94 to $0.95(n=85)$ for pre testing. The retesting showed that the Cronbach's alpha ranged between 0.94 to $0.98(n=734)$ indicating good internal consistency. The data were analysed (SPSS 16.0 for Windows, United States) using descriptive statistics and summarized as means \pm standard deviation or as percentages, when appropriate.

\section{RESULTS}

Of the 734 athletes who participated in this survey, $56 \%$ were males and the rest were females (Table 1 ). The majority of the athletes have had less than 6 years of competitive experience, with only $14.6 \%$ of them having more than 7 years of competitive experience (Table 1).

\section{Training:}

Table 2 shows the athletes' perception towards the effects of the Ramadan fast on their sports performance and training routines. All the Muslim athletes observed the Ramadan fast. Ninety-one percent of the males performed the Ramadan fast for the entire month whereas only $14.9 \%$ of the females did so. Approximately $24 \%$ of the athletes reported that the Ramadan fast had an impact on their sporting performance. Interestingly; of these, a small percentage (7.8\%) felt that Ramadan fasting seemed to enhance their sporting performances, whereas the remaining athletes (17.4\%) perceived that Ramadan fasting had

The breakdown of the effects of Ramadan fasting on sports participation by sport type is shown in Table 2A. Athletes who reported that the Ramadan fast had an effect on their performance were observed across all sports categories. Of the athletes who reported that Ramadan had an effect on sports performance, $2.9 \%$ reported that their sporting performances were enhanced during the religious fast. Interestingly, a higher percent of athletes from the combat sports (13.4\%) and motor skill sports (10.5\%) categories reported that Ramadan fasting had no effect on sports performance.

There is a similar trend for the impact of Ramadan fasting on the quality of training, where $29.3 \%$ of

Table 1: Descriptive statistics of the participants

\begin{tabular}{|c|c|c|c|}
\hline Participants characteristics & $\begin{array}{c}\text { Male } \\
(\mathrm{N}=\mathbf{4 1 1})\end{array}$ & $\begin{array}{c}\text { Female } \\
(\mathrm{N}=323)\end{array}$ & $\begin{array}{c}\text { All } \\
(\mathrm{N}=734)\end{array}$ \\
\hline Age (years) & $16.6 \pm 2.7$ & $15.8 \pm 2.5$ & $16.3 \pm 2.6$ \\
\hline \multicolumn{4}{|l|}{ Sporting event: } \\
\hline Combat sports, n (\%) & $138(33.6)$ & $57(17.6)$ & $195(26.6)$ \\
\hline Endurance-based sports, n (\%) & $96(23.4)$ & $51(15.8)$ & $147(20.0)$ \\
\hline Skill-based sports, n (\%) & $124(30.2)$ & $91(28.2)$ & $215(29.3)$ \\
\hline Team sports, n (\%) & 53 (12.9) & $124(38.4)$ & $177(24.1)$ \\
\hline \multicolumn{4}{|l|}{ Years of participation: } \\
\hline$<3$ years, $\mathrm{n}(\%)$ & $213(51.8)$ & 138 (42.7) & $351(47.8)$ \\
\hline $4-6$ years, $n(\%)$ & $141(34.3)$ & $135(41.8)$ & $276(37.6)$ \\
\hline > 7 years, $n(\%)$ & 57 (13.9) & $50(15.5)$ & $107(14.6)$ \\
\hline
\end{tabular}


Table 2: Athletes’ perception of Ramadan fast in relation to sports performance and quality of training

\begin{tabular}{|c|c|c|c|}
\hline & $\begin{array}{c}\text { Male } \\
(\mathrm{N}=\mathbf{4 1 1})\end{array}$ & $\begin{array}{c}\text { Female } \\
(\mathrm{N}=323)\end{array}$ & $\begin{array}{c}\text { All } \\
(\mathrm{N}=734)\end{array}$ \\
\hline \multicolumn{4}{|l|}{ Observance of Ramadan fast: } \\
\hline Yes, n (\%) & $411(100.0)$ & $323(100.0)$ & $734(100.0)$ \\
\hline No, n (\%) & 0.0 & 0.0 & 0.0 \\
\hline \multicolumn{4}{|l|}{ Duration of fasting: } \\
\hline Entire month, n (\%) & $372(90.5)$ & $48(14.9)$ & $420(57.2)$ \\
\hline Some days of the month, $\mathrm{n}(\%)$ & $39(9.5)$ & $275(85.1)$ & $314(42.8)$ \\
\hline \multicolumn{4}{|l|}{ Effect on sport performance*: } \\
\hline Yes, n (\%) & $106(25.8)$ & $73(22.6)$ & $179(24.4)$ \\
\hline Increased performance, n (\%) & $32(7.8)$ & $19(5.9)$ & $51(6.9)$ \\
\hline Decreased performance, n (\%) & $74(18.0)$ & $54(16.7)$ & $128(17.4)$ \\
\hline No, n (\%) & $160(38.9)$ & $102(31.6)$ & $262(35.7)$ \\
\hline Not sure, n (\%) & $145(35.3)$ & $148(45.8)$ & 293 (39.9) \\
\hline \multicolumn{4}{|l|}{ Effect on quality of training: } \\
\hline Yes, n (\%) & $130(31.6)$ & 85 (26.3) & $215(29.3)$ \\
\hline \multicolumn{4}{|l|}{ Which aspect of training } \\
\hline Length of training, n (\%) & $63(48.5)$ & 45 (52.9) & $108(50.2)$ \\
\hline Frequency of training, $\mathrm{n}(\%)$ & 35 (26.9) & $31(36.5)$ & $66(30.7)$ \\
\hline Intensity of training, $\mathrm{n}(\%)$ & $52(40.0)$ & $28(32.9)$ & $80(37.2)$ \\
\hline Mental aspect of training, $\mathrm{n}(\%)$ & $62(47.7)$ & $44(51.8)$ & $106(49.3)$ \\
\hline No, n (\%) & $140(34.1)$ & 109 (33.7) & 249 (33.9) \\
\hline Not Sure, n (\%) & $141(34.3)$ & 129 (39.9) & $270(36.8)$ \\
\hline
\end{tabular}

* See Table 2A for details on the effect of Ramadan fast on sports performance broken down by the type of sport participated

athletes surveyed reported that their training sessions were adversely affected. Most of these athletes indicated that the duration of training sessions was shortened and that the mental aspect of training was the major variable that was influenced by Ramadan fasting
(Table 2).

\section{Sleep Patterns:}

There was an equivocal opinion on whether Ramadan fast had any effect on their sleeping pattern (Table 3).

Table 2A: Effect of Ramadan fast on sports performance (sports type)

$\begin{array}{lcccccc}\begin{array}{c}\text { Effect on sport } \\ \text { performance }\end{array} & \text { Gender } & \begin{array}{c}\text { Combat } \\ \text { sports (\%) }\end{array} & \begin{array}{c}\text { Endurance-based } \\ \text { sports (\%) }\end{array} & \begin{array}{c}\text { Skill-based } \\ \text { sports (\%) }\end{array} & \begin{array}{c}\text { Team } \\ \text { sports (\%) }\end{array} & \text { Total } \\ \text { Yes } & \text { Male } & 34(8.3) & 26(6.3) & 23(5.6) & 23(5.6) & 106(25.8) \\ & \text { Female } & 15(4.6) & 7(2.2) & 26(8.0) & 25(7.7) & 73(22.6) \\ & \text { All } & 49(6.7) & 33(4.5) & 49(6.7) & 48(6.5) & 179(24.4) \\ \text { Yes - Increase } & \text { Male } & 13(3.2) & 3(0.7) & 8(1.9) & 8(1.9) & 32(7.8) \\ & \text { Female } & 8(2.5) & 1(0.3) & 4(1.2) & 6(1.9) & 19(5.9) \\ & \text { All } & 21(2.9) & 4(0.5) & 12(1.6) & 14(1.9) & 51(6.9) \\ \text { Yes - Decrease } & \text { Male } & 21(5.1) & 23(5.6) & 15(3.6) & 15(3.6) & 74(18.0) \\ & \text { Female } & 7(2.2) & 6(1.9) & 22(6.8) & 19(5.9) & 54(16.7) \\ & \text { All } & 28(3.8) & 29(4.0) & 37(5.0) & 34(4.6) & 128(17.4) \\ \text { No } & \text { Male } & 70(17.0) & 25(6.1) & 53(12.9) & 12(2.9) & 160(38.9) \\ & \text { Female } & 28(8.7) & 17(5.3) & 24(7.4) & 33(10.2) & 102(31.6) \\ & \text { All } & 98(13.4) & 42(5.7) & 77(10.5) & 45(6.1) & 262(35.7) \\ \text { Not Sure } & \text { Male } & 34(8.3) & 45(10.9) & 48(11.7) & 18(4.4) & 145(35.3) \\ & \text { Female } & 14(4.3) & 27(8.4) & 41(12.7) & 66(20.4) & 148(45.8) \\ & \text { All } & 48(6.5) & 72(9.8) & 89(12.1) & 84(11.4) & 293(39.9)\end{array}$


Table 3: Sleep pattern during Ramadan fasting month

\begin{tabular}{|c|c|c|c|}
\hline & $\begin{array}{c}\text { Male } \\
(\mathrm{N}=\mathbf{4 1 1})\end{array}$ & $\begin{array}{c}\text { Female } \\
(\mathbf{N}=323)\end{array}$ & $\begin{array}{c}\text { All } \\
(\mathrm{N}=734)\end{array}$ \\
\hline \multicolumn{4}{|l|}{ Effects on sleep pattern: } \\
\hline Yes, n (\%) & 159 (38.7) & $178(55.1)$ & 337 (45.9) \\
\hline No, n (\%) & $228(55.5)$ & $126(39.0)$ & $354(48.2)$ \\
\hline Not sure, n (\%) & $24(5.8)$ & $19(5.9)$ & $43(5.9)$ \\
\hline \multicolumn{4}{|l|}{ Aspects of sleep that is affected: } \\
\hline Quality, n (\%) & 19 (11.9) & $11(6.2)$ & 30 (8.9) \\
\hline Duration, n (\%) & $75(47.2)$ & 79 (44.4) & $154(45.7)$ \\
\hline Quality and duration, n (\%) & 65 (40.9) & 88 (49.4) & $153(45.4)$ \\
\hline \multicolumn{4}{|l|}{ Feeling sleepy during daytime: } \\
\hline Yes, n (\%) & $259(63.0)$ & $230(71.2)$ & $489(66.6)$ \\
\hline No, n (\%) & 123 (29.9) & $65(20.1)$ & $188(25.6)$ \\
\hline Not sure, n (\%) & $29(7.1)$ & $28(8.7)$ & $57(7.8)$ \\
\hline \multicolumn{4}{|l|}{ Taking extra nap during daytime: } \\
\hline Yes, n (\%) & $243(59.1)$ & $206(63.8)$ & $449(61.2)$ \\
\hline \multicolumn{4}{|l|}{ Length of nap: } \\
\hline$<1$ hour, n $(\%)$ & $71(29.2)$ & $83(40.3)$ & $154(34.3)$ \\
\hline $1-2$ hours, $n(\%)$ & $117(48.1)$ & 89 (43.2) & $206(45.9)$ \\
\hline$>2$ hours, $\mathrm{n}(\%)$ & $55(22.6)$ & 34 (16.5) & 89 (19.8) \\
\hline No, n (\%) & $148(36.0)$ & $89(27.6)$ & 237 (32.3) \\
\hline Not sure, n (\%) & $20(4.9)$ & $28(8.6)$ & $48(6.5)$ \\
\hline
\end{tabular}

Of those athletes who claimed that their sleep patterns were altered, about $45.9 \%$ complained of a reduction in sleeping duration and $45.4 \%$ reported that both the quality and duration of their sleep was affected. The majority of athletes (66.6\%) reported feeling extra sleepy during the daytime of the Ramadan month and $61.2 \%$ of these athletes took extra naps between 1- 2 hours in the daytime during the fasting month.

\section{Dietary Patterns}

Table 4 presents data on the athletes' dietary patterns during the month of Ramadan. One third of the athletes thought that they ate less than usual during Ramadan and about $25.6 \%$ stated that they actually ate more. Many of the athletes (41.4\%) perceived they had maintained their caloric intake during Ramadan. With regard to fluid intake, $76.2 \%$ of athletes increased their fluid consumption during Ramadan with $47.8 \%$ of them reporting that they very often felt dehydrated (Table 4).

Most athletes (56.1\%) did not snack between the Iftar (breaking-fast meal) and Sahur (start-of-fast meal), however, $34.6 \%$ actually snacked during the night.
Athletes (56.1\%) perceived that they had lost some body weight at the end of Ramadan. In contrast, some male $(9.8 \%)$ and $6.8 \%$ of female athletes stated there was an increase in body weight at the conclusion of Ramadan (Table 4).

\section{DISCUSSION}

The present study explored the perception of Juniorlevel Malaysian Muslim male and female athletes from a variety of sports disciplines regarding the impact of Ramadan fasting on their competitive and training performances, dietary intake and sleeping patterns. An understanding of the impact of Ramadan fasting on athletes' training, sleep and dietary pattern is warranted because this allows the coaches to better plan and possibly assist their athletes in adopting specific strategies to cope better whilst training and competing during the month of Ramadan. 
Table 4: Dietary patterns during Ramadan fast

\begin{tabular}{|c|c|c|c|}
\hline & $\begin{array}{c}\text { Male } \\
(\mathrm{N}=\mathbf{4 1 1})\end{array}$ & $\begin{array}{c}\text { Female } \\
(\mathrm{N}=323)\end{array}$ & $\begin{array}{c}\text { All } \\
(N=734)\end{array}$ \\
\hline \multicolumn{4}{|l|}{ Amount of calories intake: } \\
\hline Eat more, n (\%) & $128(31.1)$ & $60(18.6)$ & $188(25.6)$ \\
\hline Eat less, n (\%) & $110(26.8)$ & 132 (40.9) & $242(33.0)$ \\
\hline Same amount, n (\%) & $173(42.1)$ & $131(40.5)$ & $304(41.4)$ \\
\hline \multicolumn{4}{|l|}{ Volume of fluid intake: } \\
\hline Drink more, n (\%) & 308 (74.9) & $252(77.7)$ & 559 (76.2) \\
\hline Drink less, n (\%) & $36(8.8)$ & $31(9.6)$ & $67(9.1)$ \\
\hline Same amount, n (\%) & $67(16.3)$ & $41(12.7)$ & $108(14.7)$ \\
\hline \multicolumn{4}{|l|}{ Additional snack intake: } \\
\hline Yes, n (\%) & $115(28.0)$ & $139(43.0)$ & $254(34.6)$ \\
\hline No, n (\%) & 269 (65.5) & $143(44.3)$ & $412(56.1)$ \\
\hline Not sure, n (\%) & $27(6.5)$ & $41(12.7)$ & $68(9.3)$ \\
\hline \multicolumn{4}{|c|}{ Perception on body weight during Ramadan fasting: } \\
\hline Increased, n (\%) & $40(9.8)$ & $22(6.8)$ & $62(8.5)$ \\
\hline Decreased, n (\%) & $220(53.5)$ & $192(59.4)$ & $412(56.1)$ \\
\hline Unchanged, n (\%) & $151(36.7)$ & 109 (33.7) & $260(35.4)$ \\
\hline \multicolumn{4}{|c|}{ Perceived feeling of dehydration during daytime: } \\
\hline Yes, n (\%) & $176(42.8)$ & $175(54.2)$ & $351(47.8)$ \\
\hline No, n (\%) & $152(37.0)$ & $82(25.4)$ & 234 (31.9) \\
\hline Not sure, n (\%) & $83(20.2)$ & $66(20.4)$ & 149 (20.3) \\
\hline
\end{tabular}

\section{Impact of Ramadan on Sport Performance and Training}

In Table 2, there seems to be a vast difference in the number of males and females who performed the fast for the duration of the entire month. There is however, a logical reason for this discrepancy. According to the rules of Ramadan fasting, women who are menstruating are prohibited from performing the religious fast. Given that the menstrual cycle runs every 28 days and each menstrual cycle could last from five to as many as 10 days, there is thus a very high likelihood that a woman would not be performing the compulsory Ramadan fast for some days at some point in time during the Ramadan month. Certain health issues accounted for the small percentage of male athletes abstaining from fasting during Ramadan of 2009. Since the study focuses on the perception during Ramadan, it is unlikely that the results of this survey would influence the overall outcome of this study.

It is worth noting that at least $35.7 \%$ of the athletes did not think there was any negative influence of Ramadan fasting on their sport performance when competing during the fasting month (Table 2). This view concurred with some previous studies that have directly examined the impact of Ramadan fasting on exercise performance. For example, Kirkendall et al ${ }^{[12]}$ recently reported that Ramadan fasting did not have any effect on several physical performance tests (e.g., sprints, beep test, vertical jump) in youth soccer players. Karli et al ${ }^{[13]}$ showed that the Ramadan fast did not result in any detrimental effect on the anaerobic capacity of elite male strength-power athletes during 30 s all-out maximal cycling exercise. Another study on elite male junior judo athletes showed that the intermittent Ramadan fasting had minimal effect on the athletes' aerobic and anaerobic performances ${ }^{[14]}$. It must be highlighted that in all the above studies cited, the athletes continued to train during the Ramadan month and it may be reasoned that these athletes experienced some positive training-induced adaptations. Notwithstanding this view however, in contrast, $17.4 \%$ of the athletes surveyed in the present study perceived that their performance was negatively affected by Ramadan fasting. Whilst this percentage is relatively small, their views are in agreement with some previous studies that have found significant 
decrease in athletic performance capacities in Muslim athletes who were observing Ramadan fast ${ }^{[15-17]}$. While no specific causes could be attributed at this point, we believe that the athletes who reported that they were negatively affected by Ramadan may not have adopted to any coping strategies during fasting. This survey only intended to identify the athletes' perception during Ramadan, thus specific attributions towards negative or positive effects were outside the scope of our investigation.

Given the acute lack of food and fluid during the day, it would be expected that if Ramadan fasting does indeed have an adverse effect on sports performance, it would be expected to be primarily in athletes involved in physically-dominated sports such as endurance and martial art sports. Thus it was interesting to note that the negative influence of Ramadan fasting, though small, was observed across all the sports categories including those of skilled-based sports athletes (Table 2A). This indicates that Ramadan fasting may also negatively influence the non-physical aspects of sporting performance, such as arousal, attention, alertness, concentration, motivation or other 'mental' aspects of the young athlete. Indeed, several previous studies have shown that Ramadan fasting can lead to significant decline in cognitive and perceptual activities such as reaction or response time, movement reaction time, visual perception, and even short-term memory ${ }^{[5,18-22]}$. It is speculated that negative influences may be either due to a lowering of blood glucose or accumulated sleep deficit ${ }^{[3]}$. This finding implies that coaches of skills-based sports should be more aware and concerned of the possible impact of Ramadan fasting on their athletes.

It is interesting that some of the athletes (6.9\%) highlighted that their performance improved during Ramadan (Table 2A). It is thus appropriate to speculate the reason for this view. Firstly, it is believable that the spiritual act of Ramadan fasting itself and the personal beliefs of sacrifice and self-control provided the athletes with somewhat positive state of mind, resulting in mobilising psychological resources leading to a perceived enhancement in sporting performance ${ }^{[10]}$. The fasted athletes may perhaps be more determined (i.e., mentally stronger or have a stronger desire and/or motivation) to do well during their sporting activities as the impact of psychologically-induced inhibitions upon human muscular performance are well documented ${ }^{[23,24]}$. Secondly, there is a possibility of a substantial loss in body fat during Ramadan fasting ${ }^{[25,26]}$. Such decrease in body fat (and hence mass), for the weight-category or weight-bearing events such as combat sports and long distance running, can be advantageous since this implies a higher power to weight ratio and also less unnecessary weight to be transported. It must be kept in mind that these arguments are merely anecdotal evidence and thus experimental research is required to support these views.

Scientific data on athlete training sessions (i.e. intensity, duration, frequency and volume) during Ramadan fasting as compared to a non Ramadan fasting month is lacking ${ }^{[27,28]}$ and hence the association between the Ramadan fast and training adaptation have not been well established in athletes. In this study, all aspects of training variables were reported to be affected by Ramadan fasting, albeit a majority of the participants reported the length of training and the mental aspect of training as primary factors. Intensity of training during Ramadan was also greatly influenced, with the majority of athletes reporting that training in the Ramadan month was carried out primarily at moderate intensity. These findings are pertinent because it supports previous studies' observations of a lowered training load during the Ramadan fasting month as compared to the nonRamadan period ${ }^{[29-31]}$. Thus, the lack of sufficient training stimulus over the prolonged Ramadan period, particularly in well-trained athletes, may possibly lead to 'detraining' effects ${ }^{[32]}$. Hence it is clearly important for coaches to determine what is the best 'combination' of training variables to try to either improve or at least maintain the physical condition of the Ramadan fasted athletes.

Gender differences were evident in the perception of athletes of the influence of Ramadan on sporting performance and on training quality (Table 2). The majority of the female athletes were uncertain if Ramadan had an effect on sports performance or on the quality of training as compared to their male counterparts. A possible confounding factor is the fact that female athletes may have not fasted for some days 
during the Ramadan month due to menstruation and therefore, they would not have been negatively influenced by the perturbations of Ramadan fasting during those days.

\section{Impact of Ramadan on Sleep Pattern}

During Ramadan, Muslims wake up early to consume the sahur meal and this will lead to 1-2 hours of sleep loss per day. Losing 1-2 hours sleep over consecutive days can lead to chronic sleep deprivation that may affect performance, cause mood swings and bring about lethargic feelings, which in turn can increase the overall fatigue-levels in fasted Muslims ${ }^{[33]}$. In support, it was observed that $63 \%$ and $71 \%$ of the male and female athletes respectively, in the present study suffered extra daytime sleepiness during Ramadan (Table 3). However, this view of excessive daytime sleepiness is not in parallel with the data reported by many of the same athletes (61\%), which had taken 1-2 hours of daytime naps during the same period. This seems to suggest that there is a poor relationship between daytime sleepiness and acute sleep deficit, at least among Ramadan fasting subjects ${ }^{[17]}$. Nevertheless, the study on fasting young male footballers by Leiper et al ${ }^{[34]}$ reported that having about 1 hour less sleep every night throughout Ramadan but with a total night sleep time averaging more than 8 hours, did not compromise sleep quality and appears to be in line with the findings in the present study (Table 3).

\section{Impact of Ramadan on Food and Fluid Intake:}

Although the frequency of meal sitting is reduced, it is crucial to maintain sufficient caloric intake as excessive energy deficit can lead to a loss in muscle mass and inability to sustain power during exercise ${ }^{[35,}$ ${ }^{36]}$. Most athletes (41.4\%) participating in the present study felt that they consumed a similar amount of calories during Ramadan fasting compared to other days. It was interesting to observe that, $34.6 \%$ of the athletes snacked during the period between breakingfast (sunset) and starting-fast (sunrise), while 56.1\% of the athletes did not snack (Table 4). The overall results of the dietary pattern of the athletes seems to negate the common belief that Muslims are inclined to overcompensate for the reduction in meal frequency by increasing the total amount of food uptake ${ }^{[37,38]}$.
Indeed, the Ramadan fast is only intermittent in nature, not total, i.e. with no prohibition to the amount of food and fluid intake during the permissible period. This view is supported by the observation that there are more than $35 \%$ of the fasting athletes who reported that their body weight remained unchanged at the end of the Ramadan month. Therefore, the total amount of food intake in Muslim junior athletes during the period of Ramadan is not necessarily reduced when compared to their intake during the other months, which is consistent with other recent studies' findings ${ }^{[16,39,40]}$.

Arguably fluid intake, as compared to food intake, is even more critical in athletes, particularly for optimal thermoregulation during exercise. The majority of athletes (76.2\%) in the present study felt that they consumed more fluid than usual throughout the Ramadan months (Table 4). This is probably the only strategy in which athletes compensate for the inability to consume fluid during the daytime. Nevertheless, the athletes felt dehydrated during the day. No direct measurement of hydration status was taken in the present study and thus it is unclear why there was a feeling of being dehydrated while there was actually an excessive fluid intake over the period. This phenomenon could be rationalised by the fact that athletes were exercising in hot and humid environmental conditions. Alternatively, it may be that the athletes in the present study did not really consume as much as they perceived they had drank.

\section{Limitations of study:}

The survey could only determine the subjective perception of the athletes, and we were not able to provide direct evidence. However, the data consisted of a large number of athletes who, although at Juniorlevel, are training and competing at a high level of sporting prowess. It must be noted that the findings of the present study are specific to Malaysian Muslim athletes. Further research is needed to ascertain crosscultural evidence for athletes from other countries observing Ramadan fasting. Gaining an accurate perception is difficult, as the participants are likely to be guided by personal values and prevailing social customs in different cultures. Therefore, sensitivity to socio-cultural differences is essential before generalizing the findings. 


\section{CONCLUSION}

The data indicated that the majority of Malaysian Muslim Junior-level athletes did not perceive that fasting during the Ramadan month would cause an adverse effect on their competitive sports performance. The same group of athletes also had diverse opinions about the impact of the Ramadan fast on the quality of their training. Most of the athletes also did not consider their sleep patterns to have been modified despite many of them experiencing daytime sleepiness. Most athletes believe that they consumed the same amount of food before and during Ramadan, but almost all of them felt that they consumed relatively more fluids during Ramadan. The diverse findings probably indicate individual differences in the athlete's adaptability and coping strategies during fasting and training in
Ramadan. The findings of this study could assist the coaches to better plan and possibly assist their athletes in adopting specific strategies to cope better whilst training and competing during the month of Ramadan.

\section{ACKNOWLEDGMENTS}

The authors would like to thank all participants and staff of the satellite centres of the National Sports Institute of Malaysia for undertaking this survey. This study was supported by USM Incentive grant.

Conflict of interests: The authors have no conflicts of interest with regard to this manuscript.

\section{REFERENCES}

1. Sakr AH. Fasting in Islam. J Am Diet Assoc 1975;67:17-21.

2. Chaouachi A, Leiper JB, Souissi N, et al. Effects of Ramadan intermittent fasting on sports performance and training: A review. Int J Sports Physiol Perf 2009;4:419-34.

3. Aziz AR, Png W. Practical tips to exercise training during the Ramadan fasting month. ISN Bull 2008;1:13-9.

4. Roky R, Houti I, Moussamih S, et al. Physiological and chronological changes during Ramadan intermittent fasting. Ann Nutr Metab 2004;48:296-303.

5. Roky R, Iraki L, HajKhlifa R, et al. Daytime alertness, mood, psychomotor performances, and oral temperature during Ramadan intermittent fasting. Ann Nutr Metab 2000;44:101-7.

6. Waterhouse J. Effects of Ramadan on physical performance: chronobiological considerations. Br J Sports Med 2010;44:50915.

7. Ramadan J. Does fasting during Ramadan alter body composition, blood constituents and physical performance? Med Princ Pract 2002;11:41-6.

8. Waterhouse J, Alkib L, Reilly T. Effects of Ramadan upon Fluid and Food Intake, Fatigue, and Physical, Mental, and Social Activities: A Comparison between the UK and Libya. Chronobiol Int 2008;25:697-724.

9. Waterhouse J, Alabed H, Edwards B, et al. Changes in sleep, mood and subjective and objective responses to physical performance during the daytime in Ramadan. Biol Rhythm Res 2009;40:367-83.

10. Roy J, Ooi CH, Singh R, et al. Self-generated coping strategies among Muslim athletes during Ramadan fasting. J Spt Sci Med 2011;10:137-44

11. Ooi CH, Roy J, Mohd Ghazali MZ, et al. Ramadan fasting and sports performance: A Malaysian perspective. Proceedings of the III International Conference of Physical Education and Sports Science 2010;Pp:187-93.

12. Kirkendall DT, Leiper JB, Bartagi G, et al. The influence of Ramadan on physical performance measures in young Muslim footballers. J Sports Sci 2008;26:S15-27.

13. Karli U, Guvenc A, Aslan A, et al. Influence of Ramadan fasting on anaerobic performance and recovery following short time high intensity exercise. J Sports Sci Med 2007;6:490-7.

14. Chaouachi A, Coutts AJ, Chamari K, et al. Effect of Ramadan intermittent fasting on aerobic and anaerobic performance and perception of fatigue in male elite judo athletes. J Strength Cond Res 2009;23:2702-9. 
15. Zerguini Y, Kirkendall D, Junge A, et al. Impact of Ramadan on physical performance in professional soccer players. $B r \mathrm{~J}$ Sports Med 2007;41:398-400.

16. Meckel Y, Ismaeel A, Eliakim A. The effect of the Ramadan fast on physical performance and dietary habits in adolescent soccer players. Eur J Appl Physiol 2008;102:651-7.

17. Aziz AR, Wahid MF, Png W, et al. Effects of Ramadan fasting on 60 min of endurance running performance in moderately trained men. Br J Sport Med 2010;44:516-21.

18. Ali MR, Amir T. Effects of fasting on visual flicker fusion. Percept Motor Skills 1989;69:627-31.

19. Dolu N, Yüksek A, Sizer A, et al. Arousal and continuous attention during Ramadan intermittent fasting. J Basic Clin Physiol Pharmacol 2007;18:315-22.

20. Hakkou F, Warot D, Jaounen C. Does Ramadan impair vigilance and memory? Psychopharmacology 1988;96:213.

21. Lotfi S, Madani M, Abassi A, et al. CNS activation, reaction time, blood pressure and heart rate variation during Ramadan intermittent fasting and exercise. World J Sports Sci 2010a;3:37-43.

22. Lotfi S, Madani M, Tazi A, et al. Variation of cognitive functions and glycemia during physical exercise in Ramadan fasting. Rev Neurol (Paris) 2010b;166:721-6. [In French]

23. Ikai M, Steinhaus AH. Some factors modifying the expression of human strength. J Appl Physiol 1961;16:157-63.

24. Shephard RJ. Sleep, biorhythms and human performance. Sports Med 1984;1:11-37.

25. Bouhlel E, Salhi Z, Bouhlel H, et al. Effects of Ramadan fasting on fuel oxidation during exercise in trained male rugby players. Diabetes Metab 2006;32:617-24.

26. Stannard SR, Thompson MW. The effect of participation in Ramadan on substrate selection during submaximal cycling exercise. J Sci Med Sport 2008;11:510-17.

27. Leiper JB, Watson P, Evans G, et al. Intensity of a training session during Ramadan in fasting and non-fasting Tunisian youth football players. J Sports Sci 2008;26:S71-S79.

28. Aziz AR, Chia MYH, Singh R, et al. Effects of Ramadan fasting on perceived exercise intensity during high-intensity interval training sessions in elite youth soccer players. Int J Sports Sci Coach 2011;16:87-98.

29. Chennaoui M, Desgorces F, Drogou C, et al. Effects of Ramadan fasting on physical performance and metabolic, hormonal, and inflammatory parameters in middle-distance runners. Appl Physiol Nutr Metab 2009;34:587-94.

30. Coutts AJ, Chamari K, Rampinini E, et al. (2008). Monitoring training in football: measuring and periodising training. In: Dellal A (ed). From training to performance in soccer. Paris, France: De Boeck Universite. 2008; Pp:242-63.

31. Meckel Y, Ismaeel A, Eliakim A. The effect of the Ramadan fast on physical performance and dietary habits in adolescent soccer players. Eur J Appl Physiol 2008;102:651-57.

32. Mujika I, Chaouachi A, Chamari K. Precompetition taper and nutritional strategies: special reference to training during Ramadan intermittent fast. Br J Sports Med 2010;44:495-501.

33. Reilly T, Waterhouse J. Altered sleep-wake cycles and food intake: the Ramadan model. Physiol Behav 2007;90:219-28.

34. Leiper JB, Junge A, Maughan RJ, et al. Alteration of subjective feelings in football players undertaking their usual training and match schedule during the Ramadan fast. J Sports Sci 2008;26:S55-S69.

35. Bigard AX, Boussif M, Chalabi H, et al. Alterations in muscular performance and orthostatic tolerance during Ramadan. Aviat Space Environ Med 1998;69:341-6.

36. Souissi N, Souissi H, Sahli S, et al. Effect of Ramadan on the diurnal variation in short-term high power output. Chronobiol Int 2007;24:991-1007.

37. Roky R, Houti I, Moussamih S, et al. Physiological and chronobiological changes during Ramadan intermittent fasting. Ann Nutr Metab 2004;48:296-303.

38. Husain R, Duncan MT, Cheah SH, et al. Effects of fasting in Ramadan on tropical Asiatic Muslims. Br J Nutr 1987;58:41-8.

39. Al-Hourani HM, Atoum MF. Body composition, nutrient intake and physical activity patterns in young women during Ramadan. Singapore Med J 2007;48:906-10.

40. Chaouachi A, Chamari K, Roky R, et al. Lipid profiles of judo athletes during Ramadan. Int J Sports Med 2008;29:282-88. 